\title{
Densification and dielectric properties of barium neodymium titanium oxide ceramics
}

\author{
Chung-Hsin Lu*, Yung-Hsiang Huang \\ Electronic and Electro-optical Ceramics Laboratory, Department of Chemical Engineering, National Taiwan University, Taipei, Taiwan, ROC
}

Received 5 November 2002; accepted 12 November 2002

\begin{abstract}
The effects of $\mathrm{B}_{2} \mathrm{O}_{3}$-doping on the sintering behavior and dielectric properties of $\mathrm{BaNd}_{2} \mathrm{Ti}_{5} \mathrm{O}_{14}(\mathrm{BNT})$ ceramics were investigated in this study. The addition of $\mathrm{B}_{2} \mathrm{O}_{3}$ significantly enhanced the sinterability of BNT and lowered the required sintering temperatures. When the doping amount of $\mathrm{B}_{2} \mathrm{O}_{3}$ was $\leqslant 2.0 \mathrm{wt} . \%$, BNT was well densified via a liquid-phase sintering mechanism. The dielectric constants of these samples markedly increased with an increase in the doping amounts of $\mathrm{B}_{2} \mathrm{O}_{3}$. However, when 5.0 wt.\% $\mathrm{B}_{2} \mathrm{O}_{3}$ was doped, BNT was partially decomposed to form large pillar-like $\mathrm{Ba}_{2} \mathrm{Ti}_{9} \mathrm{O}_{20}$ grains, causing the samples to expand and thereby reducing the sintering density. The expansion of samples and the low dielectric constant of $\mathrm{Ba}_{2} \mathrm{Ti}_{9} \mathrm{O}_{20}$ phase both contributed to the reduction in the dielectric constant of the over-doped samples. It reveals that the doping amounts of $\mathrm{B}_{2} \mathrm{O}_{3}$ should be well controlled for facilitating the sintering process and increasing the dielectric constants of BNT ceramics.
\end{abstract}

(C) 2002 Elsevier Science B.V. All rights reserved.

Keywords: Densification; Dielectrics; Microstructure; Barium; Neodymium; Titanium; Oxide

\section{Introduction}

Recently microwave dielectric materials are extensively investigated because of their growing potential for the applications to mobile communication systems [15]. The desirable characteristics of the microwave materials include low dielectric loss, high quality factor, high dielectric constant and small temperature coefficient of resonant frequency [6,7]. The compounds existing in $\mathrm{Ba}-\mathrm{Nd}-\mathrm{Ti}-\mathrm{O}$ system have been reported to possess excellent dielectric properties and temperature stability, and can be used in microwave devices [8-11]. This system is composed of mixed compounds such as $\mathrm{BaNd}_{2} \mathrm{Ti}_{5} \mathrm{O}_{14}(\mathrm{BNT}), \mathrm{BaNd}_{2} \mathrm{Ti}_{4} \mathrm{O}_{12}$, and $\mathrm{BaNd}_{2} \mathrm{Ti}_{3} \mathrm{O}_{10}$ [12]. BNT has been known as an important microwave dielectric material; however, its sinterability is insufficient. Therefore, the sintering of BNT at a temperature as high as $1380{ }^{\circ} \mathrm{C}$ is required [13]. To cofire BNT with inner metal electrodes (such as silver) which have low

\footnotetext{
* Corresponding author.

E-mail address: chlu@ccms.ntu.edu.tw (C.-H. Lu).
}

melting points, lowering the sintering temperatures of BNT is necessary [14].

In the present study, we adopted the concept of liquid-phase sintering to facilitate the sintering process of BNT [15-19] and utilized $\mathrm{B}_{2} \mathrm{O}_{3}$ as a sintering-aid. The effects of doping amounts of $\mathrm{B}_{2} \mathrm{O}_{3}$ and sintering conditions on the densities of BNT ceramics were investigated. The phase formation and microstructural variation during the sintering process were examined. In addition, the relation between the sintering conditions and the dielectric properties of $\mathrm{B}_{2} \mathrm{O}_{3}$-doped $\mathrm{BNT}$ was also investigated.

\section{Experimental}

The solid-state reaction method was employed to synthesize BNT powders. Reagent-grade powders of $\mathrm{BaCO}_{3}$ ( $>99 \%$ pure), $\mathrm{Nd}_{2} \mathrm{O}_{3}$ ( $>99.9 \%$ pure) and $\mathrm{TiO}_{2}$ ( $>99.9 \%$ pure) were mixed stoichiometrically with ethanol $\left(\mathrm{C}_{2} \mathrm{H}_{5} \mathrm{OH}\right)$ as the starting materials. These materials were ball-milled with $\mathrm{ZrO}_{2}$ balls for $24 \mathrm{~h}$. After drying, the ball-milled materials were calcined at $1200{ }^{\circ} \mathrm{C}$ for $3 \mathrm{~h}$. Then the calcined powders were 
pressed at $25 \mathrm{~kg} \mathrm{~cm}^{-2}$ to form pellets, followed by sintering at $1300-1400{ }^{\circ} \mathrm{C}$ for $3 \mathrm{~h}$ to yield the single phase of BNT. After pure BNT powders was synthesized, $0.5-5.0$ wt. $\%$ of the densification reagent-boron oxide $\left(\mathrm{B}_{2} \mathrm{O}_{3}\right)$ was doped into BNT powders. Then the $\mathrm{B}_{2} \mathrm{O}_{3}$-doped samples were sintered at temperatures ranging from 900 to $1300{ }^{\circ} \mathrm{C}$ in air.

The density and shrinkage of the sintered samples were measured, and the phases in the sintered samples were analyzed via X-ray diffraction (XRD) using $\mathrm{CuK} \alpha$ radiation. The effects of $\mathrm{B}_{2} \mathrm{O}_{3}$ doping on the microstructures of BNT were examined by scanning electron microscopy (SEM). The dielectric properties of the sintered ceramics were measured at $1 \mathrm{MHz}$ from 25 to $150{ }^{\circ} \mathrm{C}$.

\section{Results and discussion}

The relation of the densities of undoped and $\mathrm{B}_{2} \mathrm{O}_{3}$ doped BNT ceramics vs. the sintering temperatures is depicted in Fig. 1. It was found that pure BNT was very difficult to sinter. The density of pure BNT slightly increased with a rise in sintering temperatures. Even with $1200{ }^{\circ} \mathrm{C}$ sintering, the density of the sintered samples was $3.75 \mathrm{~g} \mathrm{~cm}^{-3}$ which was only around $68 \%$ of the theoretic value $\left(5.64 \mathrm{~g} \mathrm{~cm}^{-3}\right)$ of BNT. On the other hand, once $\mathrm{B}_{2} \mathrm{O}_{3}$ was doped into $\mathrm{BNT}$, the sinterability of the samples greatly improved. When 0.5 wt. $\% \mathrm{~B}_{2} \mathrm{O}_{3}$ was added into $\mathrm{BNT}$, the relative densities of the sintered samples sintered at 1000 and $1200{ }^{\circ} \mathrm{C}$ were 77 and $92 \%$, respectively. The amounts of $\mathrm{B}_{2} \mathrm{O}_{3}$ also had significant impacts on the sintering behavior of BNT. For the $1000{ }^{\circ} \mathrm{C}$-sintered samples, when the doping amount of $\mathrm{B}_{2} \mathrm{O}_{3}$ was under $2.0 \mathrm{wt} . \%$, the density of the samples was positively correlated with the amount of $\mathrm{B}_{2} \mathrm{O}_{3}$. When 2.0 wt. $\% \mathrm{~B}_{2} \mathrm{O}_{3}$ was doped, the density reached $90 \%$. This demonstrates that adding $\mathrm{B}_{2} \mathrm{O}_{3}$ can lower the required sintering temperature of

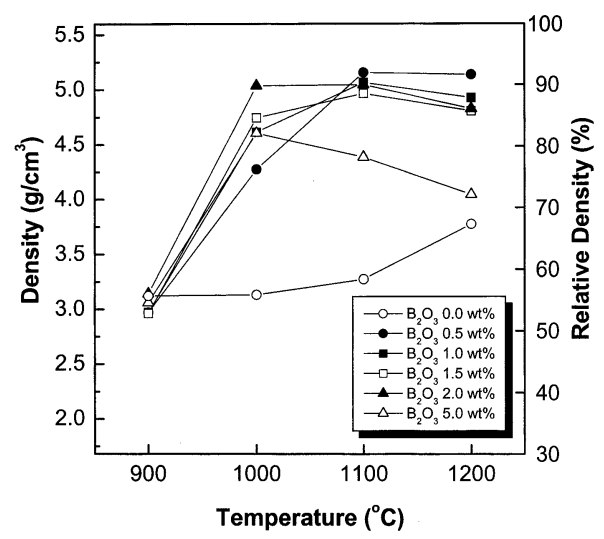

Fig. 1. Sintering densities of BNT ceramics doped with various amounts of $\mathrm{B}_{2} \mathrm{O}_{3}$.
BNT ceramics. However, as the doping amounts of $\mathrm{B}_{2} \mathrm{O}_{3}$ increased to $5.0 \mathrm{wt} . \%$, the density of the samples markedly declined to $82 \%$. It was also found that the density of the 5.0 wt. $\% \mathrm{~B}_{2} \mathrm{O}_{3}$-doped sample greatly depended on the sintering temperature. The density reached a maximum value after $1000{ }^{\circ} \mathrm{C}$-sintering, and then gradually decreased with a rise in temperature.

Fig. 2 illustrates the XRD patterns of the $1000{ }^{\circ} \mathrm{C}$ sintered samples having various contents of $\mathrm{B}_{2} \mathrm{O}_{3}$. Only BNT was detected when the doping amount of $\mathrm{B}_{2} \mathrm{O}_{3}$ was $\leqslant 1.0 \mathrm{wt} . \%$. When the doping amount of $\mathrm{B}_{2} \mathrm{O}_{3}$ increased to $1.5 \mathrm{wt} . \%$, a secondary phase- $\mathrm{Ba}_{2} \mathrm{Ti}_{9} \mathrm{O}_{20}$ was found to coexist with BNT. The more $\mathrm{B}_{2} \mathrm{O}_{3}$ was added into BNT, the more $\mathrm{Ba}_{2} \mathrm{Ti}_{9} \mathrm{O}_{20}$ was formed. The phases formed in $2.0 \mathrm{wt} . \% \mathrm{~B}_{2} \mathrm{O}_{3}$-doped $\mathrm{BNT}$ during the sintering process are shown in Fig. 3. When this sample was sintered at $900{ }^{\circ} \mathrm{C}$, BNT was the only existing compound in the sample. Once the sintering temperature reached $1000{ }^{\circ} \mathrm{C}$, the secondary phase $\mathrm{Ba}_{2} \mathrm{Ti}_{9} \mathrm{O}_{20}$ started to form. The amount of $\mathrm{Ba}_{2} \mathrm{Ti}_{9} \mathrm{O}_{20}$ monotonously increased with a rise in the sintering temperatures. Based on the above XRD results, it is demonstrated that $\mathrm{B}_{2} \mathrm{O}_{3}$ doping led to partial decomposition of BNT to produce $\mathrm{Ba}_{2} \mathrm{Ti}_{9} \mathrm{O}_{20}$ at elevated temperatures. Either increasing the doping amounts of $\mathrm{B}_{2} \mathrm{O}_{3}$ or raising the sintering temperatures will promote the decomposition of BNT.

The microstructural evolution of BNT ceramics is shown in Fig. 4. When pure BNT was sintered at $1000{ }^{\circ} \mathrm{C}$, the resulting microstructure was loose and a large numbers of pores existed among particles (Fig. 4(a)). No obvious densification occurred in this sample. When $\mathrm{B}_{2} \mathrm{O}_{3}$ was doped, a significant morphological difference was observed. As shown in Fig. 4(b), 2.0 wt.\% $\mathrm{B}_{2} \mathrm{O}_{3}$ doping resulted in significant densification of the $1000{ }^{\circ} \mathrm{C}$-heated samples and the grain growth of BNT particles. In addition, large pillar-like grains with a size of around $6 \mu \mathrm{m}$ were observed. According to the results of XRD analysis shown in Fig. 3, these grains were determined to be $\mathrm{Ba}_{2} \mathrm{Ti}_{9} \mathrm{O}_{20}$. When $5.0 \mathrm{wt} . \% \mathrm{~B}_{2} \mathrm{O}_{3}$ was doped, the morphology of BNT further varied. As

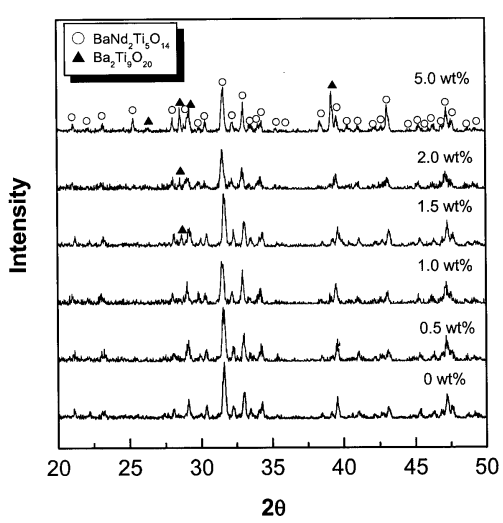

Fig. 2. XRD patterns of $1000{ }^{\circ} \mathrm{C}$-sintered BNT ceramics with various doping amounts of $\mathrm{B}_{2} \mathrm{O}_{3}$. 


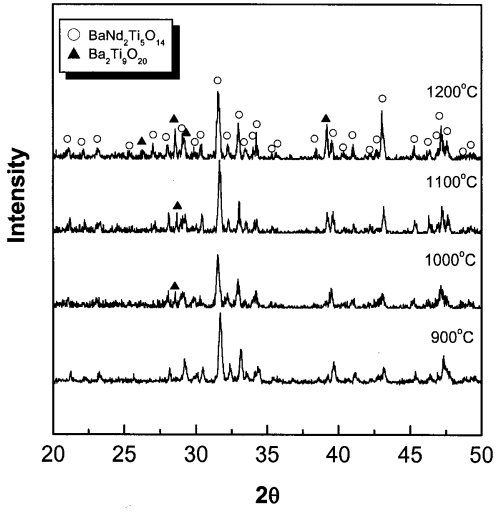

Fig. 3. XRD patterns of 2.0 wt. $\% \mathrm{~B}_{2} \mathrm{O}_{3}$-doped $\mathrm{BNT}$ ceramics sintered at various temperatures.

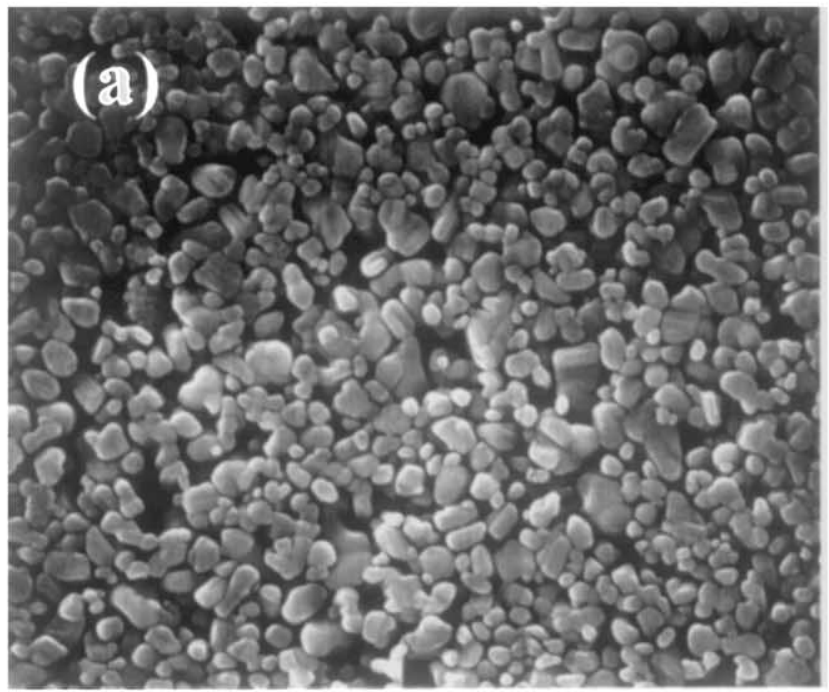

\section{$3 \mu \mathrm{m}$}

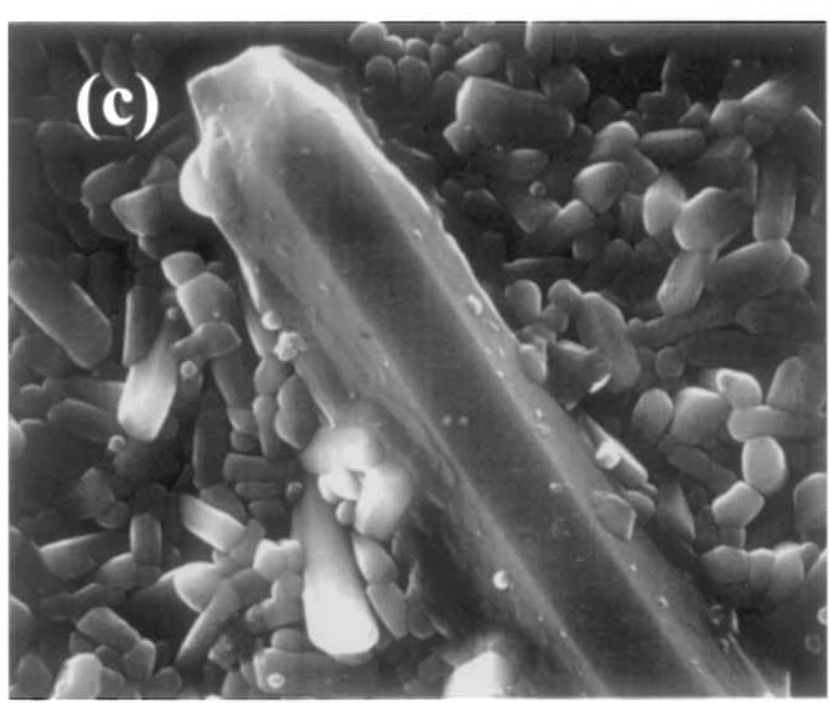

$3 \mu \mathrm{m}$ shown in Fig. 4 (c), an obvious axial grain growth occurred and columnar BNT grains with an axial length of 1-2 $\mu \mathrm{m}$ were formed. The pillar-like $\mathrm{Ba}_{2} \mathrm{Ti}_{9} \mathrm{O}_{20}$ grains also grew further to be around $10 \mu \mathrm{m}$. When raising the sintering temperature to $1200{ }^{\circ} \mathrm{C}$, this axial growth of BNT particles became more apparent and the pillar-like $\mathrm{Ba}_{2} \mathrm{Ti}_{9} \mathrm{O}_{20}$ grains further grew as indicated in Fig. 4 (d).

Since $\mathrm{B}_{2} \mathrm{O}_{3}$ exhibits a low melting point at $450{ }^{\circ} \mathrm{C}$, it serves as a sintering agent. Adding $\mathrm{B}_{2} \mathrm{O}_{3}$ can significantly improve the sinterability of BNT (Fig. 1) via a liquid-phase sintering mechanism. The liquid-phase formed by the melting of $\mathrm{B}_{2} \mathrm{O}_{3}$ results in the densification and grain growth of BNT as shown in Fig. 4(b). However, over-doping of $\mathrm{B}_{2} \mathrm{O}_{3}$ leads to the formation of

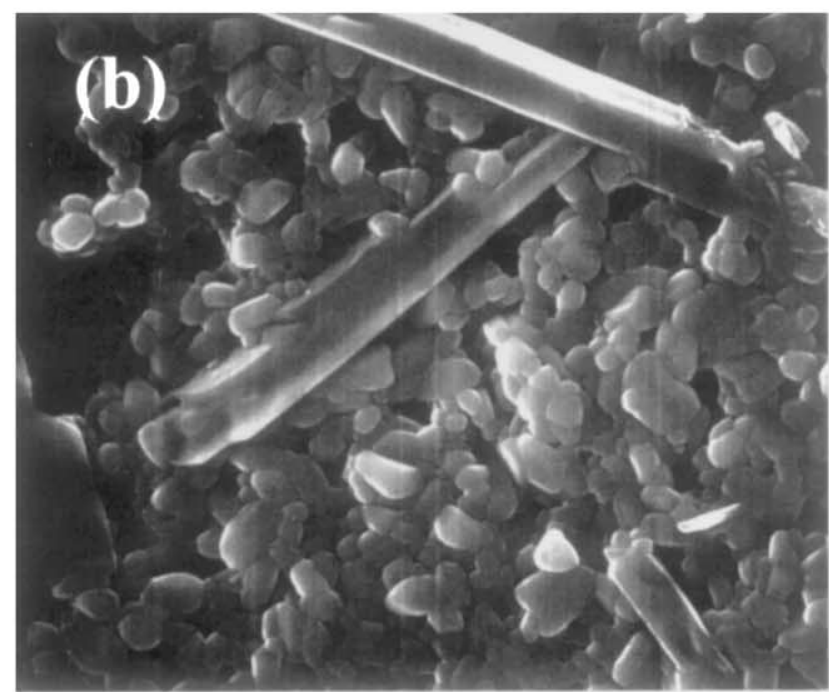

$3 \mu \mathrm{m}$

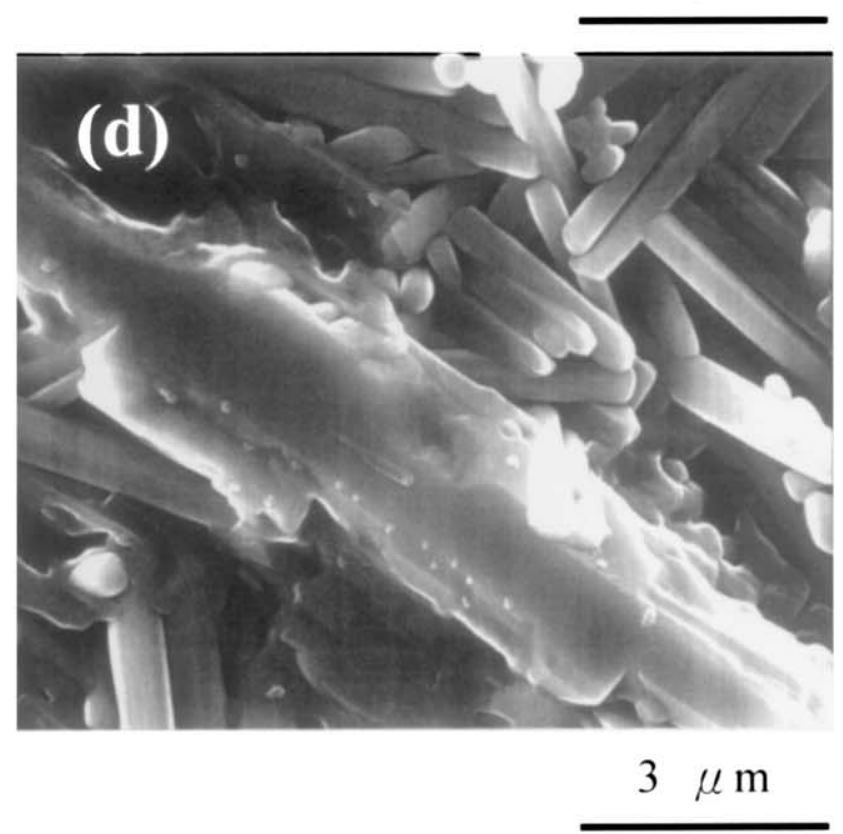

Fig. 4. SEM micrographs of undoped and $\mathrm{B}_{2} \mathrm{O}_{3}$-doped BNT ceramics. (a) The undoped sample sintered at $1000{ }^{\circ} \mathrm{C}$, (b) 2.0 wt. $\% \mathrm{~B}_{2} \mathrm{O}_{3}$-doped samples sintered at $1000{ }^{\circ} \mathrm{C}$, (c) $5.0 \mathrm{wt} . \% \mathrm{~B}_{2} \mathrm{O}_{3}$-doped samples sintered at1000 ${ }^{\circ} \mathrm{C}$, and (d) $2.0 \mathrm{wt} . \% \mathrm{~B}_{2} \mathrm{O}_{3}$-doped samples sintered at $1200{ }^{\circ} \mathrm{C}$. 


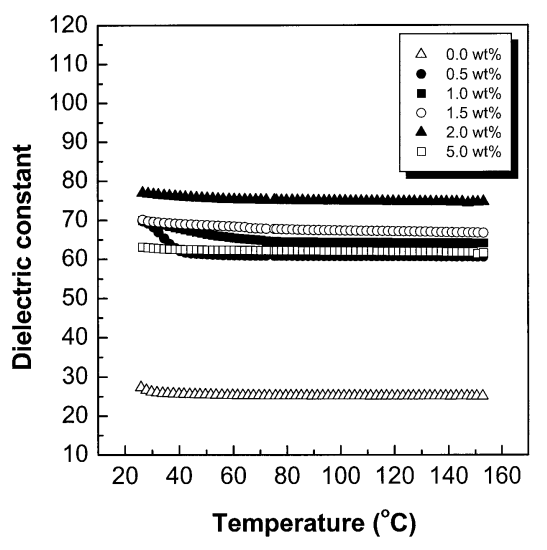

Fig. 5. Temperature dependence of the dielectric constants of $1000{ }^{\circ} \mathrm{C}$-sintered BNT ceramics doped with various amounts of $\mathrm{B}_{2} \mathrm{O}_{3}$.

the large pillar-like $\mathrm{Ba}_{2} \mathrm{Ti}_{9} \mathrm{O}_{20}$ grains (Fig. 4(c)) that cause the samples to expand and create pores in the samples. In addition, the theoretical density of $\mathrm{Ba}_{2}$ $\mathrm{Ti}_{9} \mathrm{O}_{20}\left(4.62 \mathrm{~g} \mathrm{~cm}^{-3}\right)$ is much smaller than that of BNT ceramics $\left(5.64 \mathrm{~g} \mathrm{~cm}^{-3}\right)$. Because of the expansion of the samples caused by the formation of pillar-like grains and the low density of $\mathrm{Ba}_{2} \mathrm{Ti}_{9} \mathrm{O}_{20}$, the density of the sintered samples are decreased. For the $5.0 \mathrm{wt} . \% \mathrm{~B}_{2} \mathrm{O}_{3}$ doped samples, raising the sintering temperature results in more pillar-like $\mathrm{Ba}_{2} \mathrm{Ti}_{9} \mathrm{O}_{20}$ grains which in turn decrease the density of the samples (Fig. 1).

The temperature dependence of the dielectric constants of the $1000{ }^{\circ} \mathrm{C}$-sintered samples is illustrated in Fig. 5. It was found that the dielectric constants of the sintered samples did not significantly depend on temperature. The dielectric constants of undoped BNT samples were relatively small. Within the temperature range measured $\left(25-150{ }^{\circ} \mathrm{C}\right)$, the dielectric constants were merely around 25 . When $\mathrm{B}_{2} \mathrm{O}_{3}$ was doped into $\mathrm{BNT}$, the dielectric constants of the samples significantly increased. When the doping amounts of $\mathrm{B}_{2} \mathrm{O}_{3}$ were between 0.5 and $2.0 \mathrm{wt} . \%$, the dielectric constants increased with a rise in the doping amounts of $\mathrm{B}_{2} \mathrm{O}_{3}$. The dielectric constant of $2.0 \mathrm{wt} . \% \mathrm{~B}_{2} \mathrm{O}_{3}$-doped samples markedly increased to around 76. As shown in Fig. 1, $\mathrm{B}_{2} \mathrm{O}_{3}$ doping significantly improved the sinterability of BNT. The increase in the sintering density contributed to an increase in the dielectric constants of the sintered samples. On the other hand, when the doping amount of $\mathrm{B}_{2} \mathrm{O}_{3}$ was as large as $5.0 \mathrm{wt} . \%$, the dielectric constants were markedly declined. In this sample, the pillar-like $\mathrm{Ba}_{2} \mathrm{Ti}_{9} \mathrm{O}_{20}$ grains caused the sample to expand and reduced its density as shown in Fig. 4. Moreover, the dielectric constant of $\mathrm{Ba}_{2} \mathrm{Ti}_{9} \mathrm{O}_{20}$ is smaller than the constant of BNT [20]. Therefore, the reduction in sintering density and the coexistence of the $\mathrm{Ba}_{2} \mathrm{Ti}_{9} \mathrm{O}_{20}$ phase having low dielectric constants resulted in the decrease in the dielectric constants of $5.0 \mathrm{wt} \% \mathrm{~B}_{2} \mathrm{O}_{3}$ doped sample. It reveals that adding appropriate amounts of $\mathrm{B}_{2} \mathrm{O}_{3}$ substantially influences both the sintering behavior and dielectric properties of $\mathrm{BNT}$ ceramics.

\section{Conclusions}

Pure BNT was difficult to be densified even the sintering temperature was as high as $1200{ }^{\circ} \mathrm{C}$. Once $\mathrm{B}_{2} \mathrm{O}_{3}$ was added into $\mathrm{BNT}$, the sinterability of the $\mathrm{B}_{2} \mathrm{O}_{3^{-}}$ doped samples was greatly improved. When the doping amount of $\mathrm{B}_{2} \mathrm{O}_{3}$ was $\leqslant 2.0$ wt. $\%$, BNT was well densified through a liquid-phase sintering process, and the sintering temperature was effectively lowered to $1000{ }^{\circ} \mathrm{C}$. On the other hand, when 5.0 wt. $\% \mathrm{~B}_{2} \mathrm{O}_{3}$ was doped, partial decomposition of BNT occurred and large pillar-like $\mathrm{Ba}_{2} \mathrm{Ti}_{9} \mathrm{O}_{20}$ grains were produced. The formation of these pillar-like grains resulted in the expansion of the samples and a decrease in the sintering density. The doping amounts of $\mathrm{B}_{2} \mathrm{O}_{3}$ were also found to substantially influence the dielectric constants of BNT ceramics. When the content of $\mathrm{B}_{2} \mathrm{O}_{3}$ in $\mathrm{BNT}$ was $\leqslant 2.0$ wt. \%, the dielectric constants of the samples significantly increased with a rise in the doping amount of $\mathrm{B}_{2} \mathrm{O}_{3}$. However, 5.0 wt. $\% \mathrm{~B}_{2} \mathrm{O}_{3}$ doping caused the dielectric constants to reduce because of the expansion of the samples and the coexistence of $\mathrm{Ba}_{2} \mathrm{Ti}_{9} \mathrm{O}_{20}$ phase having a low dielectric constant. Therefore, controlling the contents of $\mathrm{B}_{2} \mathrm{O}_{3}$ is crucial to facilitate the sintering process and increase the dielectric constants of BNT ceramics.

\section{References}

[1] H. Sreemoolanadhan, M.T. Sebastian, P. Mphanan, Brit. Ceram. Trans. 95 (1996) 79.

[2] K. Wakino, T. Nishikawa, Y. Ishikawa, Brit. Ceram. Trans. J. 89 (1990) 39.

[3] X.M. Chen, J.S. Yang, J. Eur. Ceram. Soc. 19 (1999) 139.

[4] J.P. Mercurio, M. Manier, B. Frit, Mater. Lett. 8 (1989) 112.

[5] A. Silva, F. Azough, R. Freer, C. Leach, J. Eur. Ceram. Soc. 20 (2000) 2727.

[6] D. Kajfez, P. Guillon, Dielectric Resonators, Artech House, Norwood, MA, 1986.

[7] E.A. Nenasheva, N.F. Kartenko, J. Eur. Ceram. Soc. 21 (2001) 2697.

[8] X.M. Chen, Y. Suzuki, N. Sato, Mater. Lett. 16 (1993) 75.

[9] D. Kolar, S. Gaberscek, B. Volavsek, J. Solid State Chem. 38 (1981) 158.

[10] H. Ohsato, S. Nishigaki, T. Okuda, Jap. J. Appl. Phys. 31 (1992) 3136.

[11] J.H. Choi, J.H. Kim, B.T. Lee, Y.M. Kim, J.H. Moon, Mater. Lett. 44 (2000) 29.

[12] A. Yamada, Y. Utsumi, H. Watarai, Jap. J. Appl. Phys. 30 (1991) 2350 . 
[13] X.M. Chen, Y. Suzuki, N. Sato, J. Mater. Sci.-Mater. El. 6 (1995) 10.

[14] D.F.K. Hennings, J. Eur. Ceram. Soc. 21 (2001) 1637.

[15] C.H. Lu, J. Am. Ceram. Soc. 77 (1994) 2529.

[16] C.H. Lu, W.S. Hwang, J. Ceram. Soc. Jap. 104 (1996) 587.

[17] C.H. Lu, Y.C. Chen, J. Euro. Ceram. Soc. 19 (1999) 2909.
[18] E.R. Nielsen, E. Ringgaard, M. Kosec, J. Eur. Ceram. Soc. 22 (2002) 1847.

[19] S.M. Rhim, H. Bak, S. Hong, O.K. Kim, J. Am. Ceram. Soc. 83 (2000) 3009.

[20] C.L. Huang, M.H. Weng, C.T. Lion, C.C. Wu, Mater. Res. Bull. $35(2000) 2445$. 